\title{
Chronic Budd-Chiari syndrome
}

\author{
Bhupinder Singh DM, Budnur C. Srinivas DM
}

Cite as: CMAJ 2018 June 4;190:E689. doi: 10.1503/cmaj.180120

A 49-year-old man presented to the outpatient department with gradually progressive pedal edema and dull aching pain in the right hypochondrium. He had no history of venous intervention or hemodialysis.

On examination, we found bilateral lower limb pitting pedal edema, mildly tender hepatomegaly, a distended abdomen, and dilated and tortuous superficial veins on the patient's abdominal wall (Figure $1 \mathrm{~A}$ ), with a filling pattern from below upward. Results from liver enzymes and function tests were abnormal: a total serum bilirubin level of 55 (normal range 1.7 to 20 ) $\mu \mathrm{mol} / \mathrm{L}$, aspartate aminotransferase level of 130 (normal range 0 to 40 ) IU/L, alanine aminotransferase level of 250 (normal range 0 to 40) IU/L and serum albumin level of 15 (normal range 35 to 55) g/L.

A two-dimensional echocardiogram showed a dilated inferior vena cava with substantial turbulence at the junction of the inferior vena cava and right atrium. We performed an ascending venogram (Figure 1B; a video [Appendix 1] is available at www. cmaj.ca/lookup/suppl/doi:10.1503/cmaj.180120/-/DC1), which confirmed critical narrowing of the suprahepatic portion of the inferior vena cava with collateralization, suggesting a membranous subtype of Budd-Chiari syndrome.

Our patient underwent percutaneous endovascular treatment (a video [Appendix 2] is available at www.cmaj.ca/lookup/suppl/ doi:10.1503/cmaj.180120/-/DC1; Appendix 3, available at www.cmaj. ca/lookup/suppl/doi:10.1503/cmaj.180120/-/DC1) with a Wallstent endoprosthesis $\left(18 \times 60 \mathrm{~mm}^{2}\right.$, Boston Scientific), followed by six months of oral anticoagulants. One month following the procedure, he had improved clinically, with normalization of liver tests and disappearance of pedal edema and abdominal varices.

Budd-Chiari syndrome is uncommon (estimated incidence of 0.87 per million population per year), characterized by either thrombotic or nonthrombotic occlusion of hepatic venous outflow. Its presentation includes pedal edema, ascites and, uncommonly, acute hepatic failure. ${ }^{1,2}$ In Asia, the membranous subtype is most often described, whereas thrombotic obstruction is the predominant cause found in western countries. ${ }^{3}$ Therapeutic options include medical management, surgical correction, percutaneous endovascular options, such as in situ thrombolysis, balloon dilatation and stenting, and liver transplant in selected patients. ${ }^{2,3}$

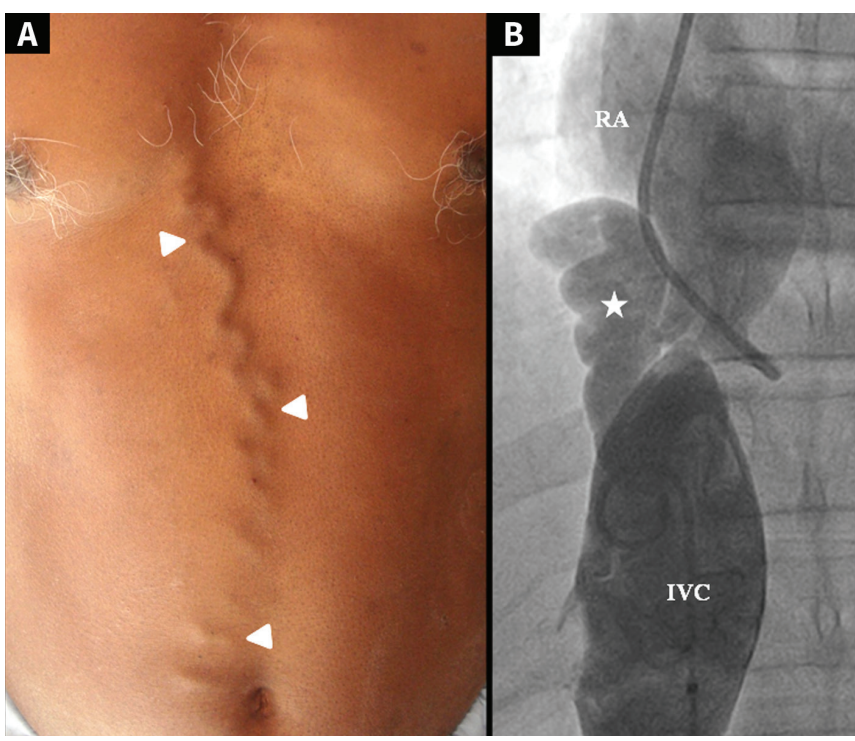

Figure 1: (A) Dilated and tortuous superficial vein (arrowheads) on the anterior abdominal wall of a 49-year-old man with chronic Budd-Chiari syndrome. (B) Ascending venogram showing critical narrowing at the suprahepatic segment of the IVC with large collateral $\left({ }^{*}\right)$. Note: IVC = inferior vena cava, $\mathrm{RA}=$ right atrium .

\section{References}

1. Ki M, Choi HY, Kim KA, et al. Incidence, prevalence and complications of BuddChiari syndrome in South Korea: a nationwide, population-based study. Liver Int 2016;36:1067-73.

2. Darwish Murad S, Plessier A, Hernandez-Guerra M, et al. EN-Vie (European Network for Vascular Disorders of the Liver). Etiology, management, and outcome of the Budd-Chiari syndrome. Ann Intern Med 2009;151:167-75.

3. Mahmoud AE, Mendoza A, Meshikhes AN, et al. Clinical spectrum, investigations and treatment of Budd-Chiari syndrome. QJM 1996;89:37-43.

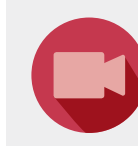

Please see the following videos online:

Ascending venography in Budd-Chiari syndrome (Appendix 1)

Percutaneous endovascular treatment in Budd-Chiari syndrome (Appendix 2)

Available at www.cmaj.ca/lookup/suppl/doi:10.1503/ cmaj.180120/-/DC1

\section{Competing interests: None declared.}

This article has been peer reviewed.

The authors have obtained patient consent.
Affiliations: Department of Cardiology (Singh), Dayanand Medical College and Hospital, Ludhiana, Punjab, India; Department of Cardiology (Srinivas), Sri Jayadeva Institute of Cardiovascular Sciences and Research, Bangalore, India
Correspondence to: Bhupider Singh, dr_bhupinders@yahoo.in 